Houwen, S. van, Lucassen, P., Stappers, H.W., Assendelft, P.J.J., Dulmen, S. van, Olde Hartman, T.C. Medically unexplained symptoms: the person, the symptoms and the dialogue. Family

\begin{tabular}{|l|l|}
$\begin{array}{l}\text { Postprint } \\
\text { Version }\end{array}$ & 1.0 \\
\hline Journal website & $\underline{\text { http://dx.doi.org/10.1093/fampra/cmw132 }}$ \\
\hline Pubmed link & $\underline{\text { https://www.ncbi.nlm.nih.gov/pubmed/28122842 }}$ \\
\hline DOI & $10.1093 /$ fampra/cmw132
\end{tabular}

This is a NIVEL certified Post Print, more info at http://www.nivel.eu

\title{
Medically unexplained symptoms: the person, the symptoms and the dialogue
}

\author{
JuUl HOUWEN ${ }^{\mathrm{A}}$, , Peter L B J LuCASSEN ${ }^{\mathrm{A}}$, Hugo W STAPPERS ${ }^{\mathrm{A}}$, Pim J J ASSENDElFT ${ }^{\mathrm{A}}$, \\ SANDRA VAN DULMEN ${ }^{\mathrm{A}},{ }_{\mathrm{B}}^{\mathrm{C}}$, AND TIM C OLDE HARTMAN ${ }^{\mathrm{A}}$ \\ ${ }^{a}$ Department of Primary and Community Care, Radboud University Nijmegen Medical \\ Centre, Nijmegen, The Netherlands, \\ ${ }^{\mathrm{b}}$ NIVEL (Netherlands institute for health services research), Utrecht, The Netherlands and \\ ${ }^{\mathrm{c}}$ Faculty of Health Sciences, University College of Southeast Norway, Drammen, Norway.
}

\begin{abstract}
Background. Many general practitioners (GPs) find the care for patients with medically unexplained symptoms (MUS) challenging. The patients themselves are often not satisfied with the care they receive.

Objectives. The aim of this study is to explore what patients with MUS expect from their GP by looking at relevant communication elements in consultations as identified by patients.

Methods. We video-recorded everyday consultations with GPs and asked the GPs immediately after the consultation whether MUS were presented. The patients in these MUS consultations were asked to reflect on the consultation during a semi-structured interview while watching a recording of their own MUS consultation. The interviews were analysed qualitatively according to the principles of constant comparative analysis.

Results. Of the 393 video-recorded consultations, 43 concerned MUS. All MUS patients said that they wanted to be taken seriously. According to the patients, their feeling of being taken seriously is enhanced when the GP: (i) pays empathic attention to them as individuals, meaning that the GP knows their personal circumstances and has an open and empathic approach, (ii) ensures a good conversation by treating the patient as an equal partner and (iii) is attentive to their symptoms by exploring these symptoms in depth and by acting on them. Conclusion. Like chronic patients, patients with MUS value a personalised approach in which GPs pay attention to patients' personal circumstances, to proper somatic management of their symptoms and to a proper conversation in which they are treated as equal partners. Use of these basic consultation skills may greatly improve care of MUS patients.
\end{abstract}


Houwen, S. van, Lucassen, P., Stappers, H.W., Assendelft, P.J.J., Dulmen, S. van, Olde Hartmah, T.C. Medically unexplained symptoms: the person, the symptoms and the dialogue. Family Practice: 2017, 34(2), 245-251

\section{INTRODUCTION}

Patients with medically unexplained symptoms (MUS, i.e. physical symptoms for which no pathological cause can be found after proper examination) are common in general practice: no underlying disease can be found for 3-10\% of the symptoms presented (1-3). MUS form a heterogeneous group of symptoms. Patients with severe MUS suffer from their symptoms, are functionally impaired, are at risk of potential iatrogenic damage due to unnecessary somatic interventions and are costly to society (4). Patients with severe MUS are often dissatisfied with the care they receive from their GP (5-7). The interaction and care provided during the clinical consultation itself may be part of the problem as there is frequently a mismatch between what MUS patients expect and what they actually receive from their GP (8). Furthermore, many doctors find patients with MUS challenging and they often feel powerless during consultations with these patients (9).

Consultation studies revealed that although GPs take more time in MUS consultations than in consultations with patients with medically explained symptoms (MES), this extra time is not spent on the exploration of patients' ideas, concerns, expectations and overall functioning (10). However, the analyses in these studies give no insight into what patients with MUS expect during the MUS consultation.

The patients' point of view regarding the consultations has only been studied indirectly through questionnaires or semi-structured interviews. These studies indicate that patients generally feel satisfied when GPs offer emotional support, provide them with a tangible explanation and show interest in their symptoms (11). Furthermore, they expect to receive a diagnosis from their GP $(12,13)$. However, these questionnaire and interview studies are subject to recall bias and are influenced by previous experiences with health care. Therefore, there is a need for a more direct study of patients' expectations and experiences with the MUS consultation in order to explore the gap between what patients with MUS want and what they actually receive during consultations. One option for such a direct approach is stimulated recall. Video-supported stimulated recall is a strategy in which video-recorded situations are replayed to the social actors involved to stimulate recall of their cognitive processes (14). The actors' thoughts, attitudes and acts are elicited by showing them excerpts from the video recording. The power of this method lies in its concrete and situational approach and the absence of recall bias. Furthermore, it focuses in depth on the actors' perspective and constitutes a unique collaboration between researchers and actors (i.e. patients with MUS).

Insight into problems in the MUS consultation itself as well as into the experiences and expectations of patients may help improve the consultation process. Our theoretical starting-point here is the biopsychosocial model according to Engel (15). Therefore, this study aims to explore relevant communication elements in MUS consultations from the patients' point of view and to identify patients' experiences and expectations with regard to their primary care MUS consultation in order to provide the GP with tools to more adequately handle patients with MUS. 
Houwen, S. van, Lucassen, P., Stappers, H.W., Assendelft, P.J.J., Dulmen, S. van, Olde Hartmah, T.C. Medically unexplained symptoms: the person, the symptoms and the dialogue. Family Practice: 2017, 34(2), 245-251

\section{METHODS}

We performed a qualitative interview study with MUS patients in which we asked them to reflect on their own video-recorded consultation. This study is part of a larger study that aims to develop an effective intervention for general practitioners, as part of the regular consultation, that is acceptable for patients with MUS.

\section{MUS study sample}

Data were collected in the primary health care setting in several primary care practices in the region of Nijmegen. Practices were phoned by one of the researchers $(\mathrm{ToH})$ to ask for participation and explanation of the study. When primary care practices agreed to participate one of the researchers $(\mathrm{JH})$ visited the practice for additional information and explanation. From April 2015 to September 2015, one of the researchers $(\mathrm{JH})$ visited the practices to invite patients, collect data, and videotape consultations during one or two days. We video-recorded all consultations by the participating GPs during one or two days. For the present study, we focused on patients who consulted the GP for MUS. Immediately after each consultation, the GP answered the following question: 'Do you think this patient has MUS?' on a 3point scale relating to the presentation of physical symptoms (1): could not be explained by a recognisable disease (i.e. MUS consultation) (2), could partly be explained by a recognisable disease (i.e. partial MUS consultation), or (3) could be explained by a recognisable disease [i.e. a consultation for medically explained symptoms (MES)]. This scale has face validity as it can easily be understood and applied by GPs during consultation hours and resembles clinical daily practice in which GPs have to interpret symptoms presented by patients as explained or unexplained by physical pathology. Previous research in this field used the same scale $(16,17)$. The researcher selected all consultations from each GP that had been identified by the GP as a MUS consultation. If fewer than three MUS consultations could be identified after one day of video-recording, we spent a second day videorecording consultations.

\section{Procedure}

Before each consultation, a researcher approached the patient in the waiting room and asked for written consent for video-recording their consultation. Patients who did not speak Dutch well and patients under 18 years old were excluded. Participating patients were video-recorded from behind and were therefore unrecognisable, while the GP was clearly visible.

As soon as possible after the consultation, patients were invited to view the recorded consultation and comment on the consultation (i.e. stimulated recall). The interviewer $(\mathrm{JH})$ informed the patients that he was interested in communication aspects of the consultation and therefore in any spontaneous reactions and comments that emerged during the viewing. These reactions and comments were audiorecorded. Each time the patient wished to comment, the video was stopped. If the patient did not comment within three minutes, the video was stopped and the following question was asked: 'What do you think of the consultation after watching it so far?' After showing the whole video, the following questions were asked: 
Houwen, S. van, Lucassen, P., Stappers, H.W., Assendelft, P.J.J., Dulmen, S. van, Olde Hartmah, T.C. Medically unexplained symptoms: the person, the symptoms and the dialogue. Family Practice: 2017, 34(2), 245-251

'Would you like to add something?', 'Have you missed anything?' and 'Is there anything that you would want to change?'

\section{Analysis}

The audio-recorded interviews (i.e. patients' reflections on the video-recorded consultation) were transcribed verbatim and analysed independently by two researchers (JH, a trainee GP and PhD student, and BZ, a medical student). They analysed the first 10 interviews according to the principles of constant comparative analysis (18). We used Atlas-ti, a software program for analysing qualitative data. The two researchers read all transcripts several times to familiarise themselves with the data. They coded relevant communication and behavioural elements. While analyzing we kept in mind the Dutch GP guideline on MUS which uses a framework that covers specific dimensions of the symptoms and pays attention to improving doctor-patient communication and maintaining the doctor-patient relationship (19). The symptom dimensions (somatic, cognitive, emotional, social and behavioural) are rooted in the biopsychosocial model (15). The biopsychosocial model assumes that the symptoms presented by patients always have somatic, cognitive, emotional, social and behavioural dimensions and that the experience of symptoms takes place in a constant interaction with the environment. Each analysis was compared and discussed in a consensus meeting after each interview. New codes emerging in the discussions were applied to the transcripts. After 10 interviews, the two researchers defined the categories independently of each other and discussed these with a senior researcher (ToH, a GP and researcher). During the analysis we constantly matched the developing categories with the transcripts. To make sure that no new categories could be found, all remaining 29 interviews were coded using this framework by one of the authors $(\mathrm{JH})$. Saturation was reached because no new categories were found during this coding process. The results of the final analysis were discussed with a fourth researcher (PL, a GP and researcher). The concepts and themes of the communication determinants emerged through this iterative process of videorecording, patient reflection, analysis and discussion. We used the COREQ guideline for the reporting of this study (20).

\section{Ethics committee and informed consent}

The research ethics committee of the Radboud University Nijmegen Medical Center concluded that the study could be carried out in accordance with the applicable rules in the Netherlands (2015-1566). The authors took care that the patients could not be identified through the details of the stories. Written informed consent was obtained from all participating patients; patients were able to withdraw their consent at any time.

\section{RESULTS}

\section{Participating GPs}

We approached 36 GPs in the region of Nijmegen, the Netherlands, of whom 20 $(56 \%)$ agreed to participate ( 9 male and 11 female GPs). Nine practices were located in the city and 11 practices in rural areas. The GPs' years of experience ranged from two to 43. Seventeen GPs ran their own private practice, whereas the other three GPs 
Houwen, S. van, Lucassen, P., Stappers, H.W., Assendelft, P.J.J., Dulmen, S. van, Olde Hartmah, T.C. Medically unexplained symptoms: the person, the symptoms and the dialogue. Family Practice: 2017, 34(2), 245-251

were employees. The number of observed consultations labelled as MUS varied between zero and five per GP: two GPs did not identify any MUS consultations.

\section{Patients with MUS}

In total, 577 patients attended their GP during the study days in 2015. Of these 577, 68 were excluded, mostly because they were younger than 18 or did not speak Dutch well. Of the 509 eligible patients, 393 agreed to participate (77\%). Forty-three had consultations that were labelled as MUS, 36 were labelled as having partial MUS and the other patients had MES. Four MUS patients were not able to comment on their consultation: two patients were not available and two consultations were not recorded on video due to technological errors. For an overview, see Figure 1.

\section{[FIGURE 1.]}

The characteristics of the 39 MUS patients who commented on their consultation are shown in Table 1.

\section{[TABLE 1.]}

During the reflection, all patients stated several times with regard to their consultation that they wanted to be taken seriously by the GP regarding the symptoms for which they were seeking help. The patients' feeling of being taken seriously seemed to cover three main themes (1): empathic attention to the patient as an individual (2), attention to ensuring a conversation between equal partners, and (3) attention to the patient's problems and symptoms. These broader themes emerged from 16 different categories (Table 2).

\section{[TABLE 2.]}

\section{Empathic attention to the patient as an individual}

MUS patients want an 'open' and relaxed atmosphere in the consultation. Patients said that they find it easier to tell their story to doctors if there is an open atmosphere.

$P$ [patient]: But she does keep responding every time if I come along with something else wrong. I think that's really positive and really good. And it makes it easier to talk and be very open and so on. That's basically what it's like every time. [...] in general it's always really relaxed, a relaxed atmosphere. That's fantastic. (Male, aged 59, thoracic pain)

MUS patients expect doctors to be 'empathic' and also want to be supported emotionally.

P: Yes, you can't see it, but we looked at each other with tears in our eyes. And perhaps she felt it in a certain way, because she just sees how much it affects me and, yes, I do think that releases an awful lot of energy in her then.[...] and she doesn't have to put an arm round my shoulders - just notice what is going on, so I feel noticed again. (Female, aged 60, tiredness, musculoskeletal pain) 
Houwen, S. van, Lucassen, P., Stappers, H.W., Assendelft, P.J.J., Dulmen, S. van, Olde Hartman, T.C. Medically unexplained symptoms: the person, the symptoms and the dialogue. Family Practice: 2017, 34(2), 245-251

Patients also stated that they prefer continuity, in the sense of seeing the same doctor every time, because they do not want to have to tell their story over and over again. In their opinion, the doctor should 'know' their patients. They expect GPs to pick up elements from previous consultations, from their medical history and background, and bring these into the consultation. Noticing that the doctor had prepared for the consultation made them feel they were being taken seriously. However, noticing that the GP had not done this properly resulted in a feeling of irritation.

P: Look, I basically come for an appointment: I've already phoned them and told them what my problem was, but he asks me what I've come for, so you don't get the feeling that your GP has briefly checked the information you gave. I do think that's something that could be improved in these consultations because then you would have the feeling you were being taken more seriously. (Male, aged 29, musculoskeletal pain)

\section{Ensuring a conversation between equal partners}

Patients expect a 'doctor-patient relationship' in which they are seen as 'equal partners'. GPs should give them sufficient opportunity to make their own choices.

P: Because I know I can come back to this and say, well, we talked about it last time but I've found out that it's like this and it's different. And he's open to that and then you can talk about it together. I [interviewer]: Yes, right. P: It gives you room that, well, isn't so restrictive, you know. Look, if you're the GP and you say I think we should do it this way and not any other way, that's incredibly restrictive for patients. (Female, aged 49, musculoskeletal pain)

MUS patients prefer a good 'dialogue' that gives them the feeling of having genuine contact with their GP. Patients mentioned both verbal aspects, like giving feedback and talking slowly, and non-verbal communication elements, like eye contact, paying attention and nodding during important issues. Many patients mentioned the need for eye contact and attention, and most patients felt irritated when doctors were 'busy with their computers'. Even though some patients understood that it can be efficient to both listen and type at the same time, they would rather not have such an 'absent' doctor and they feared that the doctor might miss essential details of their story.

P: He looks at people properly when they're talking and even if you don't look back, he still carries on looking at his patient. I like that. He's not typing something while you're talking [...] Yes, yes, I really like that, he's got an open - what do you call it? an open attitude, a way of letting you say what it is that you want to say [...] And yes, I do like that. (Female, aged 39, tiredness)

P: He just maintains contact and he doesn't start filling things in, right? I: So how do you see that the doctor's maintaining contact with you? P: Well, by looking at you and asking questions; he also responds to what I'm saying at that point. Then I do have the feeling that he's there and he's involved with us and then I do think, well 
Houwen, S. van, Lucassen, P., Stappers, H.W., Assendelft, P.J.J., Dulmen, S. van, Olde Hartmah, T.C. Medically unexplained symptoms: the person, the symptoms and the dialogue. Family Practice: 2017, 34(2), 245-251

[...] yes, then you do feel that someone's listening to you. (Female, aged 41, pelvic pain)

Patients said that they wanted to be given the opportunity to tell their story without being interrupted by the doctor while they were talking. They expected GPs to take 'time' for the conversation.

I: OK, what is the doctor doing right? P: Well, she's listening to you, letting you finish what you have to say properly. Yeah, she really makes time for you. I mean, she does that well, there's nothing wrong with that. I: OK. You say she listens properly. How can you tell she's listening properly? P: Well, of course, when someone's sitting opposite you, you can just sense whether they're talking to you and listening to you, you can just tell. [...] and then I think, you're not being taken seriously or whatever, but this time it went really well. (Male, aged 68, shortness of breath)

According to MUS patients, a good conversation is one in which doctors are 'clear' and honest when giving information and explanations and making a plan.

$P$ : Well, if he really says I think it's like this, then he also says very clearly why he thinks it's like that and then you can discuss the matter together. [...] I think that's purely because of his honesty. [...] and I have the feeling that I can be honest and can say what it's all about and that he'll accept that. (Female, aged 49, musculoskeletal pain)

Furthermore, some MUS patients preferred a quiet atmosphere in the consultation. According to them, doctors should more often make use of helpful nonverbal communication components like eye contact, quiet facial expression and showing a relaxing body posture. Doctors should listen well while giving the patient the opportunity to tell their story without interrupting them. Some patients felt more comfortable to tell their full story when GPs express a quiet atmosphere.

I: What should a doctor do to make sure you will tell the whole story? P: It is the well-known quiet atmosphere. They should not be in a hurry. The GP should show a quiet and relaxing expression. (Male, aged 62, abdominal discomfort)

Finally, some MUS patients stated that doctors should collaborate with them on the description of the 'problem and the decision' about what to do. Patients felt irritated in cases when GPs did not collaborate with them about this.

\section{Attention to the patient's problems and complaints}

Most patients mentioned the need for 'exploration' and 'symptom management'. MUS patients wanted GPs to take the time for a thorough exploration of the symptoms and complaints. They did not like it when the GP did not go into enough depth and continued too quickly on to the next stage of the consultation. According 
Houwen, S. van, Lucassen, P., Stappers, H.W., Assendelft, P.J.J., Dulmen, S. van, Olde Hartman, T.C. Medically unexplained symptoms: the person, the symptoms and the dialogue. Family Practice: 2017, 34(2), 245-251

to patients, GPs should not only explore the somatic aspects of the complaints, but they should also pay attention to patients' ideas, thoughts and fears.

I: OK. And what you just mentioned about asking further questions, going deeper into things - what do you think of the doctor doing that? P: Well, I think that's good because otherwise you can't find the underlying causes [...]. The fact that my problems are probably due to stress: I'd never have realised that if the doctor hadn't gone on asking further questions. (Female, aged 64, abdominal discomfort)

I: What could he have done to make it a good consultation so far? P: Ask more questions about the stomach pains and do more, well... I felt it went too fast, saying oh, there's a new oil or a new medicine and I would rather ... because that's why I thought afterwards when I was going home: that I wasn't satisfied with how it went. I would rather have had him give my stomach a quick check or ask more questions like where is it exactly and so on, so, well, ask further questions. (Female, aged 27, irritable bowel syndrome)

According to patients, GPs should give proper attention to the somatic dimension of the symptoms. Many MUS patients expected the GP to pay attention to their body, as in their opinion this is necessary in order to identify the cause of the symptoms and make a diagnosis. Almost all patients expected the doctor to do a physical examination and some of them wanted additional tests. Patients expected somatic symptom management by their GPs as they wanted the symptoms to be dealt with.

P: Do you see how he does that, immediately arranges that for you? He arranges it straight away, right? The appointment with the orthopaedic consultant, right? He does that immediately because he knows that, not saying you should talk first to a physiotherapist; I don't want that. I really want H. because he is, well, I've known him for quite a long time. So he does that, right. I: OK. And how do you feel about him doing that? P: Well, fantastic, fantastic, yes, that's just fantastic. (Male, aged 77, musculoskeletal pain)

Some MUS patients mentioned the need for a clear 'explanation of the cause' of their symptoms. They said that they wanted to be clearly informed. Other patients preferred the simple reassurance from excluding some serious diagnosis.

P: She explains it very well, in my opinion. She does say it very clearly here, I think. [...] At first she said it could be an inflammation or something up with my synovial bursa. Well, she simply explains it clearly, saying no, it's not that and it's just that your muscles are a little tense from that fall and yes, she gives clear answers for my symptoms, right? (Female, aged 74, irritable bowel syndrome)

I: What do you see as the most important moment or most important part of the consultation? P: Um, the examination and what he's ruling out. It puts your mind at rest. (Female, aged 19, irritable bowel syndrome) 
Houwen, S. van, Lucassen, P., Stappers, H.W., Assendelft, P.J.J., Dulmen, S. van, Olde Hartmah, T.C. Medically unexplained symptoms: the person, the symptoms and the dialogue. Family Practice: 2017, 34(2), 245-251

Finally, some MUS patients expected the GP to 'structure' the consultation.

I: What is the doctor doing well in this part of the consultation? P: Well, the steps he went through, so listening to me first, doing an examination, the results of the examination and then he summarises, tries to say what the cause is... he does that well. (Male, aged 41, abdominal discomfort)

\section{DISCUSSION}

\section{Summary of main findings}

In this study, we asked MUS patients to identify relevant communication elements shortly after having visited their GP while watching the consultation on video. The three themes that emerged - giving attention to the patient as an individual, to the conversation and to the problems and symptoms - are essential elements for MUS patients and make them feel that they are being taken seriously. Many patients in our study stated that GPs should pay attention to their medical history as well as their personal background. This continuity of personal care is one of the core values of general practice. Furthermore, MUS patients wanted a conversation between equal partners and proper somatic management of their symptoms.

\section{Comparison with existing literature}

The importance of taking the patient seriously, paying empathic attention to the person, reassurance and explanation (13,21-23) has already been demonstrated in earlier research in MUS patients and also complies with good clinical practice. The role of nonverbal communication has been described earlier (24). Understanding of MUS patients can be improved when doctors are aware of and focus on these elements. However, a new finding is the importance, according to MUS patients, of continuity, in the sense of always having the same doctor, as a prerequisite for knowing the patient with his or her personal background. As this resembles one of the core values of primary care, GPs seem to be in the right position to treat patients with MUS. The wish for attention to be paid to the conversation itself by involving MUS patients as equal partners in the dialogue is logical given the difficulties both GPs and patients experience in the communication with one another (25). Preparation for the consultation by picking up and bringing in elements from previous consultations with regard to the symptoms, medical history and personal circumstances seems to be a communication strategy that is worthwhile and simple to practice. Attention to thorough somatic symptom management of patients with MUS is rarely mentioned in the literature. The three emerged themes -giving attention to the patient as an individual, to the conversation and to the problems and symptoms- are congruent with the description of patient-centred care $(26,27)$. Attention to the patient's reason for encounter and concerns, understanding the patient's world, finding common ground about the patient's problem and management and enhancing a continuing relationship between patient and GP are both important themes in the description of patient-centred care and are found in this study. Patient centred care is a core value for many physicians. We found that MUS 
patients want to be approached according to this model instead of the disease-centred or symptom-centred care. The theoretical framework that guided our study is the biopsychosocial model. This model can be seen as the basis of patient-centred-care. Giving attention to the person, to the conversation and to the symptoms resembles the affective, procedural and instrumental communication elements that have been described previously (28) and correspond with the doctors' main function in the consultations - solving the medical problem and creating a therapeutic relationship. Prevalence rates of MUS in primary care vary a lot in different studies, depending on the used criteria for MUS. The prevalence of MUS in this study is $11 \%$. In contrast to many other studies, we identified patients as MUS who had in the doctor's opinion medically unexplained symptoms and not for example based on duration of symptoms or other criteria.

\section{Strengths and weaknesses}

As far as we know, this is the first study in which there was direct interaction with MUS patients in order to identify important and relevant communication elements within the consultation. These results can guide the development of communication interventions in the future for patients with MUS and will enhance the acceptability of such interventions. We were able to avoid recall bias by using the method of stimulated recall, observing the consultation together with the patient. However, the analyses are based on participants' reflection and interpretations and these will be influenced by past experiences. Video consultations are used as a prompt to aid discussion, to minimize recall bias and therefore to study participants' opinions about the communication in the specific MUS consultation with as little as possible loss of detail. To obtain the best information from patients, we used a qualitative approach with a cyclical process of information gathering and analysis until data saturation was reached. Also, the data were independently analysed by two researchers.

Possible limitations of our study are the selection of MUS patients and altered communication behaviour because the consultation was being recorded (i.e. Hawthorne effect). We noticed variation between GPs in the assessment of MUS. Some GPs identified five patients with MUS during one or two days of consultations, some identified none. Moreover, GPs were asked to identify MUS based on only a single consultation for that specific complaint, while GPs often require more than one consultation in practice. However, as our focus was on studying GPs' communication behaviour with patients whom they consider to have MUS, we consider this inter-doctor variation to be less important. Finally, we cannot identify whether a patient was more or less satisfied with the MUS consultation as a whole because we did not measure this directly and because the problems mentioned in the interview about the consultation were most of the time about a part of the consultation. Video recording has been described and used in various studies (29) and no significant effects have been found on the behaviour of patients or physicians $(30,31)$. This is in line with the experiences of the patients included in our study as most of them did not notice any change in their doctor's behaviour. However, a minority did notice a change in the attitude of the doctor. Furthermore, most doctors said that they had no problem ignoring the camera, although some of them admitted some influence during the first few consultations. 
Houwen, S. van, Lucassen, P., Stappers, H.W., Assendelft, P.J.J., Dulmen, S. van, Olde Hartmah, T.C. Medically unexplained symptoms: the person, the symptoms and the dialogue. Family Practice: 2017, 34(2), 245-251

\section{Implications for further research and daily practice}

The identified communication elements will help the development of an intervention that is feasible for general practitioners and acceptable for patients with MUS. Exploring with patients what they actually want from their GP in the consultation was a first step. Patients mentioned paying attention to the patient, the conversation and the somatic symptom management. These elements are very close to those of the Calgary-Cambridge guide to medical interviews (32). Some elements of this guide, like exploration of patient's problems, understanding the patient's perspective, achieving a shared understanding and shared decision making are close to elements of patient-centred-care. Better management of patients with MUS can be achieved if GPs invest more time and energy in getting to know the background and context of the individual patients, aim at a dialogue in which the patient is treated as an equal partner and conduct an in-depth exploration of the symptoms with a focus on somatic symptom management. Explanation and reassurance will be more effective if patients feel they are being taken seriously. There is more to discover with the interpretation and analysis of the video and interview data, such as linguistic analysis of the communication used in the MUS and MES consultation and quantitative analysis of the pre- and post-consultation questionnaires of the MUS and MES consultation. We will analyze this in the near future.

\section{CONCLUSION}

Patients with MUS value a personalised approach in which GPs pay attention to patients' personal circumstances, to proper somatic management of their symptoms and to a proper conversation in which they are treated as equal partners. Use of these basic consultation skills may greatly improve care of MUS patients.

\section{Declaration}

Funding: This study is supported by ZonMw (funding number 839110010).

Ethical approval: The research ethics committee concluded that the study could be carried out without their approval.

Conflict of interest: None.

\section{ACKNOWLEDGEMENTS}

We thank Bas van der Zijden (BZ) for his work and all the GPs and patients for their cooperation in this study. 
Houwen, S. van, Lucassen, P., Stappers, H.W., Assendelft, P.J.J., Dulmen, S. van, Olde Hartmah, T.C. Medically unexplained symptoms: the person, the symptoms and the dialogue. Family

\section{REFERENCES}

1 Verhaak PF Meijer SA Visser AP Wolters G . Persistent presentation of medically unexplained symptoms in general practice. Fam Pract 2006 April 25 [Epub ahead of print].

2 Aamland $\mathrm{A}$ Malterud $\mathrm{K}$ Werner EL . Patients with persistent medically unexplained physical symptoms: a descriptive study from Norwegian general practice. BMC Fam Pract 2014 June 03 [Epub ahead of print].

3 Swanson LM Hamilton JC Feldman MD . Physician-based estimates of medically unexplained symptoms: a comparison of four case definitions. Fam Pract 2010 July 17 [Epub ahead of print].

4 Joustra ML Janssens KA Bultmann U Rosmalen JG . Functional limitations in functional somatic syndromes and well-defined medical diseases. Results from the general population cohort LifeLines. J Psychosom Res 2015 June 01 [Epub ahead of print].

5 Peters S Rogers A Salmon P et al What do patients choose to tell their doctors? Qualitative analysis of potential barriers to reattributing medically unexplained symptoms. J Gen Intern Med 2009; 24(4): 443-9.

6 Salmon P Humphris GM Ring A Davies JC Dowrick CF . Primary care consultations about medically unexplained symptoms: patient presentations and doctor responses that influence the probability of somatic intervention. Psychosom Med 2007 July 20 [Epub ahead of print].

7 Hartz AJ Noyes R Bentler SE et al Unexplained symptoms in primary care: perspectives of doctors and patients. Gen Hosp Psychiatry 2000 July 06 [Epub ahead of print].

8 Salmon P Dowrick CF Ring A Humphris GM . Voiced but unheard agendas: qualitative analysis of the psychosocial cues that patients with unexplained symptoms present to general practitioners. Br J Gen Pract 2004 March 10 [Epub ahead of print].

9 Salmon $\mathrm{P}$ Peters $S$ Clifford $\mathrm{R}$ et al Why do general practitioners decline training to improve management of medically unexplained symptoms? J Gen Intern Med 2007 April 20 [Epub ahead of print].

10 Epstein RM Shields CG Meldrum SC et al Physicians' responses to patients' medically unexplained symptoms. Psychosom Med 2006 March 24 [Epub ahead of print].

11 Deale A Wessely S . Patients' perceptions of medical care in chronic fatigue syndrome. Soc Sci Med 2001 May 16 [Epub ahead of print].

12 Johansson EE Hamberg K Lindgren G Westman G . "I've been crying my way"-qualitative analysis of a group of female patients' consultation experiences. Fam Pract 1996 December 01 [Epub ahead of print].

13 Salmon P Ring A Dowrick CF Humphris GM . What do general practice patients want when they present medically unexplained symptoms, and why do their doctors feel pressurized? J Psychosom Res 2005; 59(4): 255-60; discussion 61-2.

14 Dulmen van $B$. What makes them (not) talk about proper medication use with their patients? An analysis of the determinants of GP communication using reflective practice. Int J Pers Cent Med 2011; 1: 27-34.

15 Engel GL . The need for a new medical model: a challenge for biomedicine. Sciende 1977; 8: 129-36.

16 Ring A Dowrick CF Humphris GM Davies J Salmon P. The somatising effect of clinical consultation: what patients and doctors say and do not say when patients present medically unexplained physical symptoms. Soc Sci Med 2005; 61(7): 1505-15.

17 Salmon P Ring A Humphris GM Davies JC Dowrick CF . Primary care consultations about medically unexplained symptoms: how do patients indicate what they want? J Gen Intern Med 2009 January 24 [Epub ahead of print].

18 Glaser B SA. The Discovery of Grounded Theory . Chicago: Aldine, 1967.

19 Olde Hartman T BN Molenaar B . NHG-Standaard somatisch onvoldoende verklaarde lichamelijke klachten. Huisarts Wet 2013: 222-30.

20 Tong A Sainsbury P Craig J . Consolidated criteria for reporting qualitative research (COREQ): a 32-item checklist for interviews and focus groups. Int J Qual Health Care 2007 September 18 [Epub ahead of print]. 
Houwen, S. van, Lucassen, P., Stappers, H.W., Assendelft, P.J.J., Dulmen, S. van, Olde Hartman, T.C. Medically unexplained symptoms: the person, the symptoms and the dialogue. Family

Practice: 2017, 34(2), 245-251

21 Heijmans M Olde Hartman TC van Weel-Baumgarten E et al Experts' opinions on the management of medically unexplained symptoms in primary care. A qualitative analysis of narrative reviews and scientific editorials. Fam Pract 2011 March 04 [Epub ahead of print].

22 Olde Hartman TC Woutersen-Koch H Van der Horst HE . Medically unexplained symptoms: evidence, guidelines, and beyond. Br J Gen Pract 2013 December 20 [Epub ahead of print].

23 Malterud K . Symptoms as a source of medical knowledge: understanding medically unexplained disorders of women. Fam Med 2000; 32: 603-11.

24 Grzybowski SC Stewart MA Weston WW . Nonverbal communication and the therapeutic relationship: Leading to a better understanding of healing. Can Fam Physician 1992 September 01 [Epub ahead of print].

25 Salmon P. . Conflict, collusion or collaboration in consultations about medically unexplained symptoms: the need for a curriculum of medical explanation. Patient Educ Couns 2007; 67(3): 246-54.

26 Stewart M Brown JB Donner A et al The impact of patient-centered care on outcomes. J Fam Pract 2000 October 14 [Epub ahead of print].

27 Stewart M . Towards a global definition of patient centred care. BMJ 2001 February 27 [Epub ahead of print].

28 Bensing J . Instrumental and affective aspects of physician behavior. Med Care Res Rev 1992; 30: 283-96.

29 Fossum B Arborelius E . Patient-centred communication: videotaped consultations. Patient Educ Couns 2004 August 04 [Epub ahead of print].

30 Coleman $T$. Using video-recorded consultations for research in primary care: advantages and limitations. Fam Pract 2000 October 06 [Epub ahead of print].

31 Arborelius $E$ Timpka T . In what way may videotapes be used to get significant information about the patient-physician relationship? Med Teach 1990; 12: 197-208.

32 Calgary Cambridge Guide .

\section{TABLES AND FIGURES}

Figure 1. Flow chart of patients who visited their general practitioner during the study days. Forty-three patients were labelled as MUS, 39 of them were able to reflect on their consultation. MUS = medically unexplained symptoms, MES = medically explained symptoms.

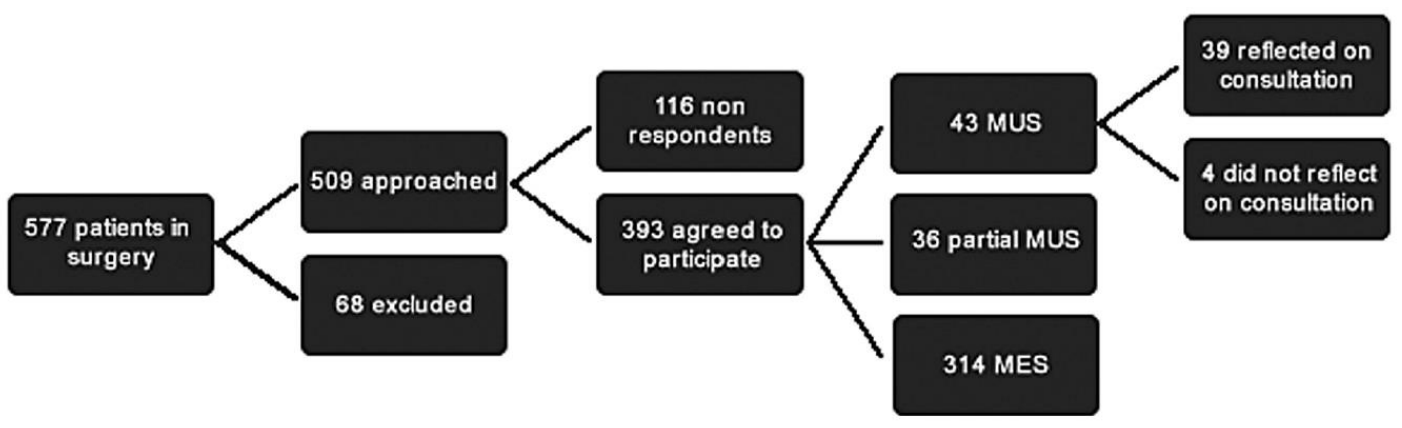


Houwen, S. van, Lucassen, P., Stappers, H.W., Assendelft, P.J.J., Dulmen, S. van, Olde Hartmąm, T.C. Medically unexplained symptoms: the person, the symptoms and the dialogue. Family

Practice: 2017, 34(2), 245-251

Table 1. Characteristics of 39 patients labelled by their GP as medically unexplained symptoms during the registration days

Patient characteristics

$\begin{array}{lc}\text { Age in years [mean (range)] } & 52.9(19-88) \\ \text { Sex }(n) & 11 \\ \quad \text { Male } & 28 \\ \quad \text { Female } & 5 \\ \text { Level of education }{ }^{a}(n) & 22 \\ \quad \text { Low } & 12 \\ \text { Medium } & \\ \text { High } & 17 \\ \text { Voluntary or paid work }(n) & 22 \\ \quad \text { Yes } & 19.4 \\ \text { No } & \\ \text { Mean time between consultation and watching video } \\ \text { (days) }\end{array}$

${ }^{a}$ Education level was classified as low (primary education), medium (secondary education) and high (pre-university and university). 
Houwen, S. van, Lucassen, P., Stappers, H.W., Assendelft, P.J.J., Dulmen, S. van, Olde Hartman, T.C. Medically unexplained symptoms: the person, the symptoms and the dialogue. Family Practice: 2017, 34(2), 245-251

Table 2. Description of theme: attention to the individual person, ensuring a conversation between equal partners and attention to patients' problems and symptoms

Taking patient seriously

1. Attention to the individual person

Open/approachable

Knowing the person

Empathy

2. Ensuring a conversation between equal partners

Dialogue

Time and space

Clarity

Equality

Quiet atmosphere

Shared problem definition and decision making 11

3. Attention to patient's problems and symptoms

Actions

Exploration

35

Identification of cause

33

Explanation

25

Reassurance

22

Structuring

Patients varied in the number of quotes. 